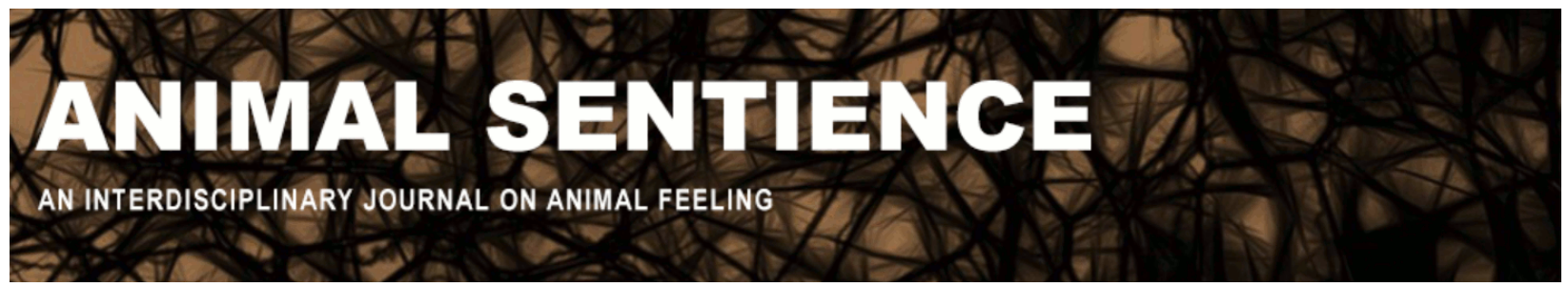

Howell, Tiffani J. (2018) Can neuroimaging in dogs have practical implications?. Animal Sentience 22(6)

DOI: $10.51291 / 2377-7478.1333$

Date of submission: 2018-05-22

Date of acceptance: 2018-05-29

(c) (†)

This article has appeared in the journal Animal

Sentience, a peer-reviewed journal on animal

cognition and feeling. It has been made open access,

free for all, by WellBeing International and deposited

in the WBI Studies Repository. For more information,

please contact

wbisr-info@wellbeingintl.org.

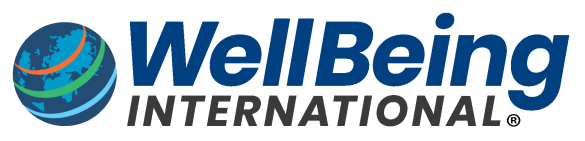

SOLUTIONS FOR PEOPLE, ANIMALS AND ENVIRONMENT 


\title{
Can neuroimaging in dogs have practical implications?
}

\author{
Commentary on Cook et al. on Dog Jealousy
}

\author{
Tiffani J. Howell \\ Anthrozoology Research Group, La Trobe University
}

\begin{abstract}
Jealousy, or at least aggression, can be observed in dogs using neuroimaging techniques, but this response attenuates quickly following repeated exposure to the aggression-inducing stimulus. This may have a practical application. Early socialisation as a puppy, and habituation as an adult dog, could help prevent undesirable behaviours such as predatory behaviour. It is unclear whether these processes are the same, and affected only by the dog's age. Neuroimaging could help us understand whether the same neurological processes underlie socialisation and habituation, and whether self-rewarding behaviours such as predatory behaviour could be stopped using socialisation/habituation techniques.
\end{abstract}
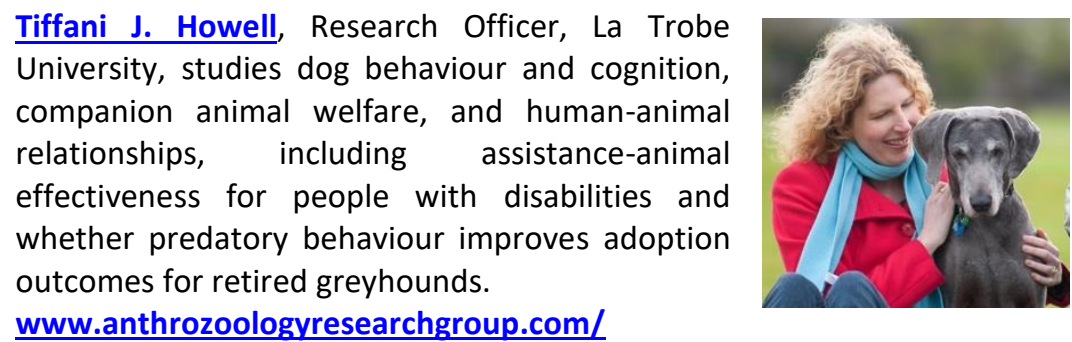

As a general rule, I am wary of extrapolating subjective experience from neuroimaging data. An EEG waveform or an fMRI scan simply cannot explain what the colour red looks like, or what a bell sounds like, or whether a dog feels jealousy the way that humans do - or even, for that matter, whether two people experience jealousy in the same way. So I raised an eyebrow when I read the title of Cook et al.'s (2018) recently published target article suggesting that jealousy in dogs could be measured using fMRI techniques. In their text, however, the authors are appropriately circumspect about what their results might actually mean, and clearly specify that the neurological responses were most clearly related to aggression. This is similar in some ways to research showing that dogs and their owners both experience increases in oxytocin during interactions (Nagasawa et al., 2015). Do dogs therefore love us the way we love them? That remains an open question. It will require a phenomenal level of research ingenuity to describe subjective experience purely through neurological responses.

In my view, Cook et al.'s most intriguing finding is not the amygdala activation when 'another dog' is given a treat but the very rapid habituation that occurs in some of the dogs when the condition is repeated. These dogs were reported by their owners to be more aggressive than the others, which led the authors to suggest that these results could provide support for 'exposure therapy' as a treatment for undesirable behaviours. That is the part of the target article that really caught my attention.

My mentor and I have recently completed a study about whether it is possible to stop predatory behaviour towards small animals in greyhounds retired from the racing industry. Predatory behaviour is one of the key factors reducing a retired racer's chances of being rehomed as a pet, so stopping it could improve adoption outcomes. According to survey and interview responses from dog behaviour modification practitioners, there are two common 
suggestions for stopping it: adequate socialisation to small animals when the greyhound is a puppy and carefully monitored, regular, safe exposure (i.e., habituation or exposure therapy) to small animals as an adult dog (unpublished data). These two recommendations may actually represent the same underlying process, which varies in practice depending on the age of the dog.

Puppy socialisation involves exposure to a wide range of experiences, objects, people, places, and other animals within the first few months of life (Battaglia, 2009). During this time, called the 'sensitive period of socialisation', puppies are particularly open to these new experiences. Because of this inherent openness at this age, an intensive process of exposure to any specific person/place/thing may be unnecessary. It is possible that habituation, which is an intensive process of exposure to a particular stimulus during the dog's adulthood, is an extension of the socialisation that should ideally occur during the sensitive period. If this is the case, perhaps it requires more careful attention than early-age socialisation because the adult dog is not as amenable to this process as the puppy, owing to changes associated with development.

Currently this is all conjecture, but neuro-imaging could help disentangle whether habituation is just the more difficult, adult dog version of socialisation. The fMRI data could be used to compare responses to various stimuli in well socialised and poorly socialised dogs, although it would require a lot of reflection to define what is meant by 'well-' and 'poorlysocialised' in the context of modern pet dogs sufficiently trained to sit still in a magnet. In a perfect world, studying $\mathrm{fMRI}$ responses in puppies as they move through the socialisation process would be very instructive but challenging from a logistical perspective; puppies typically have no interest in participating in scientific research, in my experience.

The neurological underpinnings of predatory behaviour differ from those of aggression (Panksepp \& Biven, 2012), so it would be useful to know whether habituation practices with predatory dogs would result in an attenuation of the neurological response to predatory behaviour like that observed in the amygdala by Cook et al. Aggression is a fundamentally negative affective state, whereas predatory behaviour is generally positive (Panksepp \& Biven, 2012). Would this make a difference to neurological habituation? If a dog finds predatory behaviour too rewarding inherently, perhaps habituation will never occur, or it may require too many of the finite resources of rescue and adoption organisations to be realistic. On the other hand, if specific techniques prove to decrease latency to habituation as indicated by $\mathrm{fMRI}$ data, these could then be implemented in practice.

Cook et al. present some very interesting results. Besides advancing our understanding of how dogs experience the world, applications of this technique could ultimately help improve dog welfare. 


\section{References}

Battaglia, C. L. (2009). Periods of early development and the effects of stimulation and social experiences in the canine. Journal of Veterinary Behavior: Clinical Applications and Research, 4(5), 203-210. doi:10.1016/j.jveb.2009.03.003

Cook, P., Prichard, A., Spivak, M., \& Berns, G. S. (2018). Jealousy in dogs? Evidence from brain imaging. Animal Sentience 22(1).

Nagasawa, M., Mitsui, S., En, S., Ohtani, N., Ohta, M., Sakuma, Y., Onaka, T., Mogi, K., \& Kikusui, T. (2015). Oxytocin-gaze positive loop and the coevolution of human-dog bonds. Science, 348(6232), 333-336. doi:10.1126/science.1261022

Panksepp, J., \& Biven, L. (2012). The Archaeology of Mind: Neuroevolutionary Origins of Human Emotions. New York: WW Norton \& Company. 


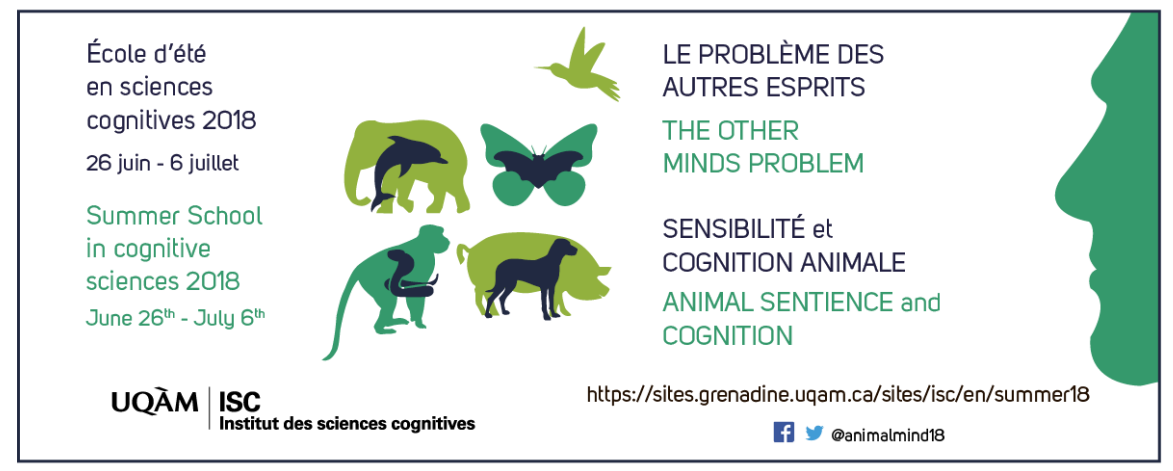

\title{
ISC 2018 Summer School in Cognitive Sciences
}

\author{
June 26 - July 6, 2018 \\ Montreal (Canada) \\ The Other Minds \\ Problem: Animal \\ Sentience and Cognition
}

Overview. Since Descartes, philosophers know there is no way to know for sure what — or whether - others feel (not even if they tell you). Science, however, is not about certainty but about probability and evidence. The 7.5 billion individual members of the human species can tell us what they are feeling. But there are 9 million other species on the planet $(20$ quintillion individuals), from elephants to jellyfish, with which humans share biological and cognitive ancestry, but not one other species can speak: Which of them can feel — and what do they feel? Their human spokespersons - the comparative psychologists, ethologists, evolutionists, and cognitive neurobiologists who are the world's leading experts in "mindreading" other species - will provide a sweeping panorama of what it feels like to be an elephant, ape, whale, cow, pig, dog, chicken, bat, fish, lizard, lobster, snail: This growing body of facts about nonhuman sentience has profound implications not only for our understanding of human cognition, but for our treatment of other sentient species.

Gregory Berns: Decoding the Dog's Mind with Awake

Neuroimaging

Gordon Burghardt: Probing the Umwelt of Reptiles

Jon Sakata: Audience Effects on Communication Signals

PANEL 1: Reptiles, Birds and Mammals

WORKSHOP 1: Kristin Andrews: The "Other" Problems: Mind, Behavior, and Agency

Sarah Brosnan: How Do Primates Feel About Their Social Partners?

Alexander Ophir: The Cognitive Ecology of Monogamy Michael Hendricks: Integrating Action and Perception in a Small Nervous System

PANEL 2: Primates, Voles and Worms

WORKSHOP 2: Jonathan Birch: Animal Sentience and the Precautionary Principle

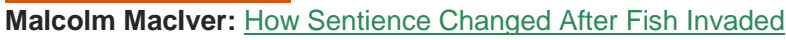
Land 385 Million Years Ago

Sarah Woolley: Neural Mechanisms of Preference in Female Songbird

Simon Reader: Animal Social Learning: Implications for Understanding Others

PANEL 3: Sea to Land to Air

WORKSHOP 3: Steven M. Wise: Nonhuman Personhood

Tomoko Ohyama: Action Selection in a Small Brain (Drosophila Maggot)

Mike Ryan: "Crazy Love": Nonlinearity and Irrationality in Mate Choice

Louis Lefebvre: Animal Innovation: From Ecology to

Neurotransmitters

PANEL 4: Maggots, Frogs and Birds: Flexibility Evolving SPECIAL EVENT: Mario Cyr: Polar Bears

Colin Chapman: Why Do We Want to Think People Are

Different?

Vladimir Pradosudov: Chickadee Spatial Cognition

Jonathan Balcombe: The Sentient World of Fishes

PANEL 5: Similarities and Differences

WORKSHOP 5 (part 1): Gary Comstock: $\underline{\text { A Cow's Concept of }}$ Her Future

WORKSHOP 5 (part 2): Jean-Jacques Kona-Boun: $\underline{\text { Physical }}$

and Mental Risks to Cattle and Horses in Rodeos

\author{
Joshua Plotnik: Thoughtful Trunks: Application of Elephant \\ Cognition for Elephant Conservation \\ Lori Marino: Who Are Dolphins? \\ Larry Young: The Neurobiology of Social Bonding, Empathy and \\ Social Loss in Monogamous Voles \\ Panel 6: Mammals All, Great and Small \\ WORKSHOP 6: Lori Marino: The Inconvenient Truth About \\ Thinking Chickens \\ Andrew Adamatzky: Slime Mould: Cognition Through \\ Computation \\ Frantisek Baluska \& Stefano Mancuso: What a Plant Knows \\ and Perceives \\ Arthur Reber: A Novel Theory of the Origin of Mind: \\ Conversations With a Caterpillar and a Bacterium \\ PANEL 7: Microbes, Molds and Plants \\ WORKSHOP 7: Suzanne Held \& Michael Mendl: Pig Cognition \\ and Why It Matters \\ James Simmons: What Is It Like To Be A Bat? \\ Debbie Kelly: Spatial Cognition in Food-Storing \\ Steve Phelps: Social Cognition Across Species \\ PANEL 8: Social Space \\ WORKSHOP 8: To be announced \\ Lars Chittka: The Mind of the Bee \\ Reuven Dukas: Insect Emotions: Mechanisms and Evolutionary \\ Biology \\ Adam Shriver: Do Human Lesion Studies Tell Us the Cortex is \\ Required for Pain Experiences? \\ PANEL 9: The Invertebrate Mind \\ WORKSHOP 9: Delcianna Winders: Nonhuman Animals in \\ Sport and Entertainment \\ Carel ten Cate: Avian Capacity for Categorization and \\ Abstraction \\ Jennifer Mather: Do Squid Have a Sense of Self? \\ Steve Chang: Neurobiology of Monkeys Thinking About Other \\ Monkeys \\ PANEL 10: Others in Mind \\ WORKSHOP 10: The Legal Status of Sentient Nonhuman \\ Species
}

